\title{
AVALIAÇÃO DA TÉCNICA DE SOLARIZAÇÃO ATRAVÉS DO MONITORAMENTO DO PERFIL DE TEMPERATURAS DO SOLO*
}

\section{EVALUATION OF SOLARIZATION TECHNIQUE THROUGH SOIL TEMPERATURE PROFILE MONITORING}

\section{Paola Machado Muniz}

Engenheira Ambiental e Sanitarista. UFFS. E-mail: paolammuniz @gmail.com

Thalía Lopes Friedrich

Graduanda em Engenharia Ambiental e Sanitária. UFFS E-mail:

thalia.friedrich27@gmail.co $\mathrm{m}$

Fabiano Cassol

Doutor em Engenharia. Universidade Federal da Fronteira Sul, Curso de Engenharia Ambiental e Sanitária. E-mail: fabiano.cassol@uffs.edu.br

\section{RESUMO}

O presente trabalho tem por objetivo avaliar a técnica de solarização através do monitoramento do perfil de temperaturas do solo e da obtenção de equações para determinar a temperatura do solo em função da temperatura do ar. A solarização foi aplicada em uma unidade experimental de $4 \mathrm{~m}^{2}$ de área. Para o monitoramento das temperaturas, efetuado tanto no terreno não solarizado quanto no local de aplicação da técnica, foram utilizados 8 termopares do tipo $\mathrm{K}$ conectados a um registrador de dados FieldLogger. O estudo analisou as temperaturas da superfície do solo e das profundidades $0,10 \mathrm{~m}, 0,25 \mathrm{~m}$ e $0,40 \mathrm{~m}$, por um período de trinta e três dias. As equações foram obtidas a partir do método de regressão linear, no qual foi ajustado uma reta para os dados amostrais e analisado o coeficiente de determinação ajustado $\left(\mathrm{R}^{2}\right)$ para cada caso. Obteve-se a temperatura máxima de $33,34{ }^{\circ} \mathrm{C}$ na superfície do solo que não recebeu o tratamento, e $36,72{ }^{\circ} \mathrm{C}$ na superfície do solo solarizado. $\mathrm{O}$ coeficiente de determinação para a área que não recebeu solarização variou entre 0,50 e 0,61 , enquanto que para o solo solarizado, o $R^{2}$ variou entre 0,36 e 0,63 .

Palavras-chave: Solarização; Agroecologia; Monitoramento Ambiental.

\section{ABSTRACT}

This work aims to evaluate the solarization technique by monitoring the soil temperature profile and obtaining equations to determine the soil temperature as a function of air temperature. Solarization was applied in a $4 \mathrm{~m}^{2}$ experimental unit. For the monitoring of temperatures, carried out both in non-solarized terrain and in the place of application of the technique, 8 type $\mathrm{K}$ thermocouples were used, connected to a FieldLogger data recorder. The study analyzed soil surface temperatures and depths $0.10 \mathrm{~m}, 0.25 \mathrm{~m}$ and $0.40 \mathrm{~m}$, for a period of thirty-three days. The equations were obtained using the linear regression method, in which a line was adjusted for the sample data and the adjusted determination coefficient $\left(\mathrm{R}^{2}\right)$ was analyzed for each case. The maximum temperature of $33.34{ }^{\circ} \mathrm{C}$ was obtained on the surface of the soil that did not receive the treatment, and $36.72{ }^{\circ} \mathrm{C}$ on the surface of the solarized soil. The coefficient of determination for the area that did not receive solarization varied between 0.50 and 0.61 , while for the solarized soil, the $\mathrm{R}^{2}$ varied between 0.36 and 0.63 .

Key-words: Solarization; Agroecology; Enviromental Monitoring.

*Artigo resultante da monografia de conclusão de curso da primeira autora, intitulada "Estudo do comportamento térmico do solo para solarização em latossolo", defendida em julho de 2019. 


\section{INTRODUÇÃO}

É notório, nos últimos anos, uma maior preocupação da sociedade com questões ambientais, movidas pela discussão acerca da utilização de defensivos agrícolas. Considera-se, ainda, a essencialidade do aproveitamento sustentável dos recursos naturais, visto que estes ainda não são utilizados da melhor maneira possível (MELO; MISAEL; SIQUEIRA, 2018) como, por exemplo, a energia e o calor provindos do sol. Evidencia-se, assim, a importância da pesquisa e aprimoramento de técnicas agrícolas sustentáveis, bem como o desenvolvimento de medidas de controle que dispensam componentes químicos.

A solarização é um método prático e econômico que realiza o aproveitamento da energia solar como fonte de calor para tratamento de áreas agrícolas em período de pré-plantio. Essa técnica consiste na utilização de um filme polimérico para cobrir a superfície do solo, capturar a irradiação solar e prolongar o aquecimento, além de realizar a transferência de calor para as camadas mais profundas do solo (KANAAN et al., 2018). A cobertura plástica também impede a evaporação da água e a emissão da radiação de comprimentos de ondas longas, modificando o fluxo de calor entre a superfície do solo e a atmosfera e promovendo um maior aquecimento do solo (KATAN, 1981).

A temperatura afeta a maioria dos processos biológicos e físicos que ocorrem no subsolo e desempenha um papel importante durante o ciclo de vida das plantas. A maioria dos microorganismos do solo mantém-se em condições ótimas de desenvolvimento em temperaturas mais baixas. Por essa razão, o aumento da temperatura durante o período de solarização pode comprometer a composição taxonômica das comunidades bacterianas (SIMMONS et al., 2014 apud KANAAN et al., 2018).

Diversos autores afirmam que o calor sob a cobertura plástica, decorrente da solarização, promove altas taxas de decomposição de compostos orgânicos no solo e, consequentemente, a liberação de substâncias químicas voláteis, como álcoois e aldeídos, que possuem uma função importante na erradicação de vários microrganismos (GAMLIEL; AUSTERWEIL; KRITZMAN, 2000), limitando o desenvolvimento de patógenos e de espécies de plantas daninhas (KATAN, 1981; HOROWITZ; REGEV; HERZLINGER, 1983). Ghini et al. (2003) relataram que a solarização reduziu significativamente a atividade microbiana do solo, além de causar inibição ao fungo Fusarium oxysporum f. sp. phaseoli, indicando a potencial aplicabilidade do método. Por estes motivos, a solarização é comumente empregada para extinguir ou reduzir patógenos, pragas e plantas daninhas de áreas destinadas ao plantio agrícola.

O método de solarização é dependente do clima e precisa ser adaptado para a região específica a ser aplicada. As condições mais favoráveis podem ser determinadas experimentalmente pela cobertura do solo e pelas temperaturas resultantes. Modelos preditivos de temperaturas facilitam esta tarefa, uma vez que a medição da temperatura do solo em diferentes profundidades não é um trabalho 
tão simples como medir a temperatura do ar. Assim, uma previsão assertiva da temperatura do solo reduz o tempo, custo e manutenção de equipamentos necessários para o monitoramento do local (AHMAD; RASUL, 2008).

Em síntese, este estudo justifica-se pela importância de desenvolver métodos de controle agrícola com boa relação custo-benefício, capazes de garantir a produtividade das culturas, de forma econômica e sustentável. Nesse contexto, o trabalho objetiva avaliar a aplicabilidade da técnica de solarização por meio do monitoramento da temperatura do solo, além de gerar equações por meio de regressão linear para estimar a temperatura em diferentes profundidades do solo.

\section{MATERIAIS E MÉTODOS}

A técnica de solarização foi aplicada em uma unidade experimental da Universidade Federal da Fronteira Sul (UFFS), Campus Cerro Largo, cujas características geográficas são: altitude média de 211 metros, coordenadas $28^{\circ} 08^{\prime} 55^{\prime \prime} \mathrm{S}$ e $54^{\circ} 44^{\prime} 17^{\prime \prime} \mathrm{W}$, na qual o solo é classificado como Latossolo Vermelho Distroférrico (SANTOS et al., 2018).

Uma área de $4 \mathrm{~m}^{2}$, ausente de cobertura vegetal, foi coberta por um filme de polietileno, com as bordas enterradas junto ao solo, evitando a dissipação de calor para o ambiente, conforme observase na Figura 1(a). O filme de polietileno utilizado é transparente, de baixa densidade (PEBD), possui $100 \mu \mathrm{m}$ de espessura e dimensões de 6x6 m.

A medição da temperatura do solo foi realizada por 8 termopares do tipo $\mathrm{K}$, previamente calibrados com a metodologia padrão estabelecida pela NBR 14610, da Associação Brasileira de Normas Técnicas (ABNT, 2010). Os sensores foram conectados a um registrador de dados FieldLogger, configurado para entrada analógica de dados e armazenamento contínuo dos resultados experimentais na sua memória interna. Quatro sensores foram direcionados para a área experimental de aplicação da solarização, e os demais para a área não solarizada, com o auxílio de duas estacas de madeira de $1 \mathrm{~m}$ de comprimento.

Figura 1 - Cobertura de polietileno (a) e posicionamento dos sensores (b) na área experimental.

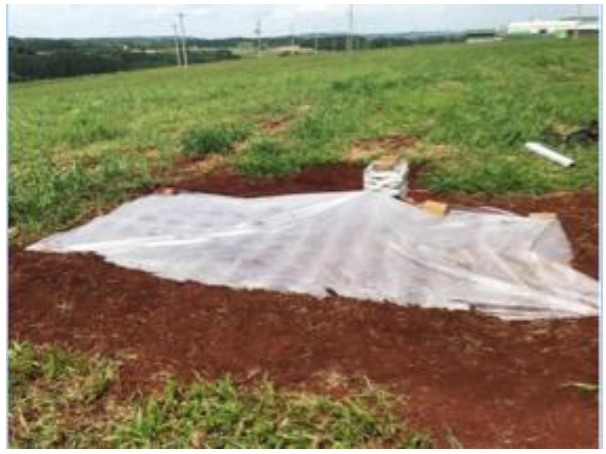

(a)

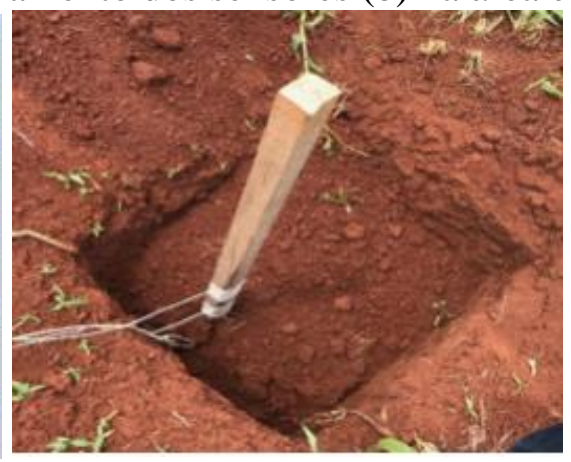

(b)

Fonte: Autores, 2019. 
Dessa maneira, o monitoramento foi efetuado tanto no terreno não solarizado quanto no local de aplicação da cobertura de polietileno, para fins de comparação, ambos para a superfície do solo, 0,10 m, 0,25 m e 0,40 m de profundidade, transcorrendo-se por um período de trinta e três dias. A Figura 1(b) apresenta os sensores posicionados em diferentes profundidades.

\subsection{ANÁLISE ESTATÍSTICA}

Para estimar a temperatura do solo em função da temperatura do ar foi realizada uma análise estatística dos dados obtidos no experimento, por meio do software RStudio. Para a obtenção de correlações entre as variáveis foi empregado o método de regressão linear, que fornece um modelo preditivo na forma de equação de uma reta (Equação 1).

$$
\mathrm{T}_{\mathrm{s}}=\alpha+\beta \mathrm{T}_{\mathrm{ar}}
$$

Na Equação 1, $\mathrm{T}_{\mathrm{s}}$ corresponde a temperatura do solo, os coeficientes $\alpha$ e $\beta$ são parâmetros do modelo, obtidos estatisticamente, e $\mathrm{T}_{\text {ar }}$ denota a temperatura do ar. Dados da temperatura do ar no local do estudo foram obtidos através de uma Estação Meteorológica Automática instalada no Campus Cerro Largo da UFFS. Foram consideradas as médias diárias das temperaturas do solo obtidas nos trinta e três dias de experimento e as respetivas temperaturas do ar, provenientes dos registros da Estação Meteorológica.

\section{RESULTADOS E DISCUSSÃO}

A partir do monitoramento de temperaturas durante o período experimental, foi verificado uma temperatura máxima de $33,34^{\circ} \mathrm{C}$ na superfície do solo que não recebeu a cobertura de polietileno, enquanto que a temperatura máxima obtida na superfície do solo solarizado foi de $36,72{ }^{\circ} \mathrm{C}$. As temperaturas máximas atingidas para as demais profundidades podem ser visualizadas nas Tabelas 1 e 2, para a área não-solarizada e para o local que recebeu a solarização, respectivamente, bem como as mínimas, medianas, médias e seus referentes desvios-padrão.

Tabela 1 - Resultados estatísticos do monitoramento da área não-solarizada.

\begin{tabular}{lllll}
\hline \multirow{2}{*}{ Profundidade $(\mathrm{cm})$} & \multicolumn{3}{l}{ Temperatura $\left({ }^{\circ} \mathrm{C}\right)$} \\
\cline { 2 - 5 } & Mínima & Máxima & Mediana & Média \pm Desvio-padrão \\
\hline 0 & 20,01 & 33,34 & 29,00 & $28,33 \pm 3,05$ \\
10 & 20,40 & 32,99 & 28,62 & $28,07 \pm 2,57$ \\
\hline
\end{tabular}




\begin{tabular}{lllll}
\hline 25 & 20,90 & 31,59 & 28,81 & $27,99 \pm 2,39$ \\
40 & 21,30 & 31,47 & 28,59 & $27,83 \pm 2,37$ \\
\hline
\end{tabular}

Fonte: Autores, 2019.

Tabela 2 - Resultados estatísticos do monitoramento da área solarizada.

\begin{tabular}{ccccc}
\hline \multirow{2}{*}{ Profundidade $(\mathrm{cm})$} & \multicolumn{3}{c}{ Temperatura $\left({ }^{\circ} \mathrm{C}\right)$} \\
\cline { 2 - 5 } & Mínima & Máxima & Mediana & Média \pm Desvio-padrão \\
\hline 0 & 20,40 & 36,72 & 30,66 & $29,94 \pm 4,10$ \\
10 & 20,70 & 36,68 & 29,32 & $29,20 \pm 4,00$ \\
25 & 20,10 & 33,59 & 29,56 & $28,63 \pm 3,50$ \\
40 & 20,00 & 33,03 & 28,78 & $28,19 \pm 3,02$ \\
\hline
\end{tabular}

Fonte: Autores, 2019.

A Figura 2 exibe as temperaturas máximas obtidas durante o período experimental nas quatro profundidades monitoradas. É perceptível uma elevação de temperatura em todas as profundidades da área de aplicação da solarização. Este aumento ocorre com maior intensidade na superfície e decresce nas camadas mais profundas do solo, devido a menor variação de temperatura nas mesmas. Assim, verifica-se a efetividade do filme de polietileno para intensificar o aquecimento do solo.

Figura 2 - Temperatura máxima do solo no período experimental em diferentes profundidades.

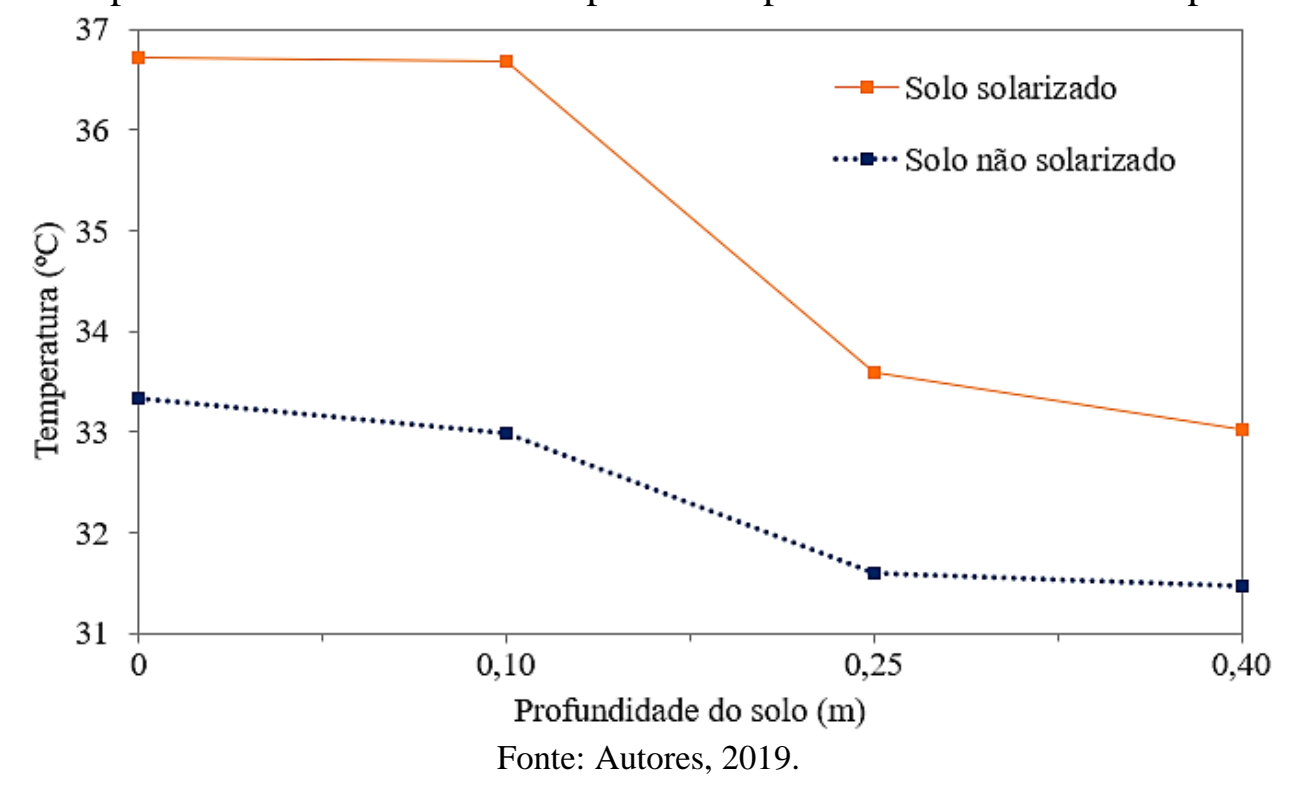

Verificou-se que o maior aumento de temperatura com a aplicação da técnica de solarização ocorreu na profundidade de 0,10 m abaixo da superfície do solo, com uma elevação de cerca de 3,7 ${ }^{\circ} \mathrm{C}$ na temperatura máxima registrada no decorrer do experimento. Durante a aplicação de solarização 
do presente estudo, a temperatura máxima do ar registrada foi de $26,14{ }^{\circ} \mathrm{C}$, com um total de 308,2 mm de precipitação pluviométrica e $1245,36 \mathrm{KW} / \mathrm{m}^{2}$ de radiação solar acumulada. Possivelmente, a elevação de temperatura não ocorreu de maneira mais significativa devido às frequentes chuvas no decorrer do período, que além da ausência da incidência solar, facilitam o resfriamento do solo.

Para uma visualização geral dos resultados, a Figura 3 descreve o comportamento da temperatura média do solo ao longo dos dias monitorados, período que se estendeu de 13/01/2019 a 01/02/2019, e posteriormente de 11/02/2019 a 23/02/2019, ilustrando a variação de temperatura obtida com a cobertura de polietileno em comparação com os valores obtidos na ausência da mesma.

Em um estudo semelhante conduzido por Kuva, Alves e Erasmo (1995), as temperaturas médias durante a solarização do solo foram $37,7^{\circ} \mathrm{C}, 38,6{ }^{\circ} \mathrm{C}$ e $35,3{ }^{\circ} \mathrm{C}$ nas profundidades $0,5 \mathrm{~m}, 0,10$ m e $0,20 \mathrm{~m}$, respectivamente, utilizando polímero transparente de $300 \mu \mathrm{m}$ de espessura. O experimento foi conduzido por um período de aproximadamente quatro meses em solo caracterizado como Latossolo Vermelho-Escuro Distrófico, em um município do sudeste brasileiro, onde o clima é mais quente comparado ao sul do Brasil, região do presente estudo. Durante o período experimental, a temperatura do ar atingiu uma máxima de $29,7^{\circ} \mathrm{C}$, justificando um melhor resultado e viabilidade da técnica avaliada para a região, além de uma duração superior de aplicação da técnica, que favorece o acúmulo de calor e alcance de temperaturas mais altas.

Figura 3 - Temperatura média do solo durante o período de monitoramento.

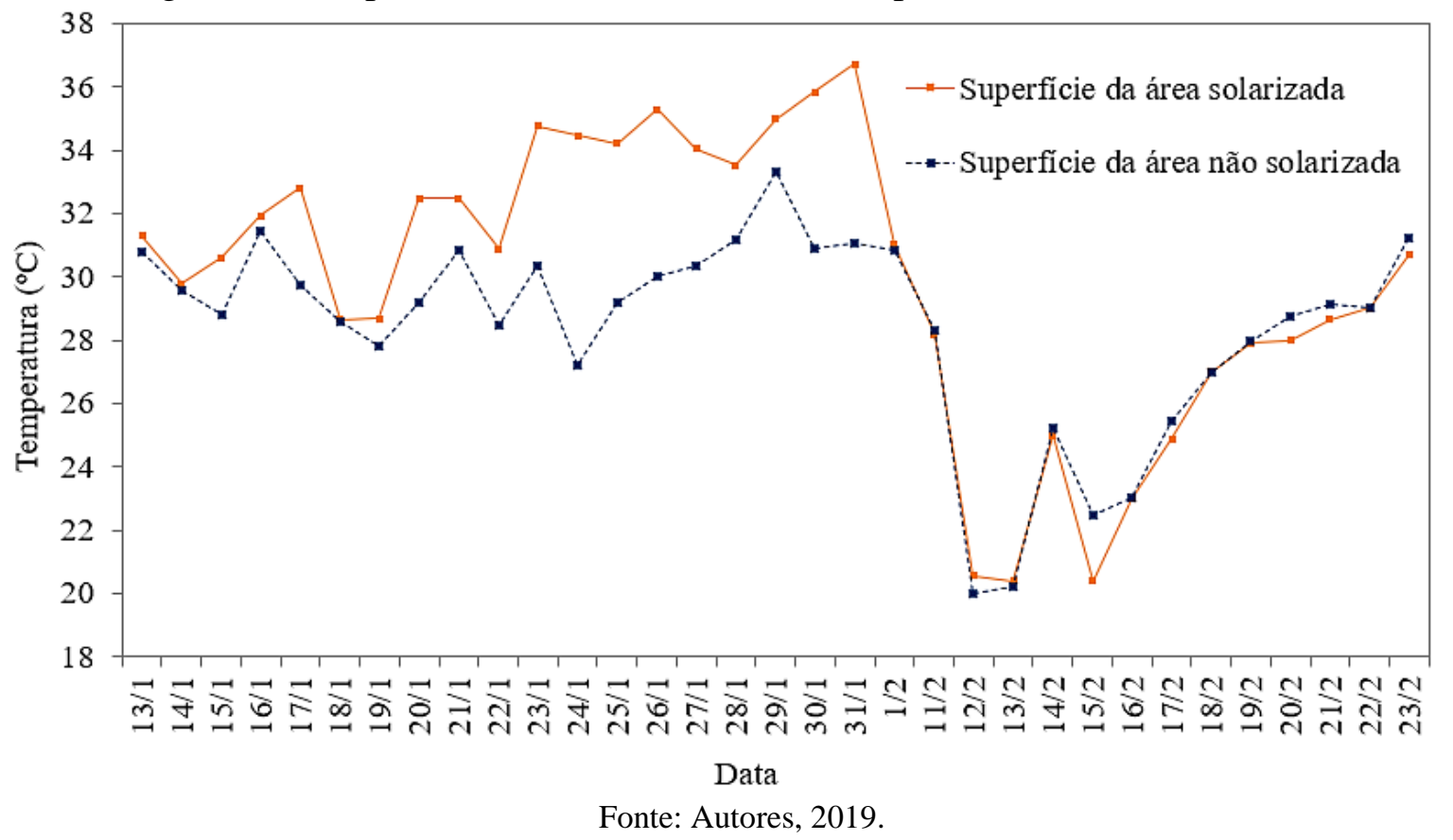

Conforme Moreira e Siqueira (2006), além de afetar as reações fisiológicas, a temperatura influencia nas características físico-químicas do solo que influenciam o ambiente de crescimento dos 
microorganismos. As reações microbianas no solo ocorrem em maior intensidade em temperaturas em torno de $28{ }^{\circ} \mathrm{C}$ e apresentam limitações de desenvolvimento em temperaturas menores que $25^{\circ} \mathrm{C}$ e maiores que $35^{\circ} \mathrm{C}$.

Portanto, os resultados demonstram que as temperaturas registradas sob o filme de polietileno neste experimento não foram suficientemente satisfatórias para a eliminação de microorganismos patógenos e efetivação da proposta de tratamento do solo, fato resultante da pouca elevação das temperaturas, decorrente de possíveis perdas de calor através do filme de polietileno, além de condições atmosféricas desfavoráveis durante o período. A Estação Meteorológica Automática da UFFS registrou um acúmulo de 308,2 mm de precipitação nos trinta e três dias de estudo, assim, as frequentes chuvas dificultaram o alcance de maiores temperaturas no solo.

\subsection{CORRELAÇÕES ESTATÍSTICAS PARA A TEMPERATURA DO SOLO}

As equações foram obtidas a partir do ajuste linear dos dados experimentais. As Figuras 4 e 5 ilustram, para cada profundidade do solo, o comportamento linear, a reta de ajuste do modelo de regressão, juntamente com a equação resultante e seu coeficiente de determinação $\left(\mathrm{R}^{2}\right)$. Nas figuras, Ts 0 é a temperatura na superfície do solo, Ts 10 é a temperatura do solo em uma profundidade de 0,1 m, Ts 25 é a temperatura do solo em uma profundidade de 0,25 m e Ts40 é a temperatura do solo em uma profundidade de $0,4 \mathrm{~m}$.

O coeficiente de determinação para a área que não recebeu solarização variou entre 0,50 e 0,61, para a profundidade de 0,4 m e para a superfície do solo, respectivamente. Constata-se, dessa maneira, que a influência da temperatura do ar ocorre com maior intensidade para a superfície do solo e diminui nas camadas posteriores.

Para o solo onde foi aplicado a solarização, o coeficiente de determinação variou entre 0,36 e 0,63 , para a profundidade de 0,4 e 0,1 m, respectivamente. A dificuldade de obter um coeficiente de determinação mais elevado pode ser justificada pela presença de outliers, que tendem a distorcer o valor da média e, consequentemente, o valor de $\mathrm{R}^{2}$ e as estimativas dos valores. Isto pode ser identificado nos gráficos, onde verifica-se que há pontos que se encontram muito distante dos demais.

Segundo Ahmad e Rasul (2008), nos períodos mais secos o solo é menos resistente à penetração de calor quando comparado com o solo molhado. Assim, a insolação recebida aquece o solo no mesmo instante. Além disso, pode ser notado que o calor específico do solo seco é menor do que o solo úmido. Portanto, a transferência de calor do ar para o solo seco ocorre de forma mais rápida. Isso pode explicar a dificuldade de elevação das temperaturas e dos coeficientes de determinação no presente estudo, visto que no período experimental foi frequente a ocorrências de chuvas. 
Figura 4 - Regressão linear para o solo não solarizado; (a) 0 m; (b) 0,1 m; (c) 0,25 m; (d)0,4m.

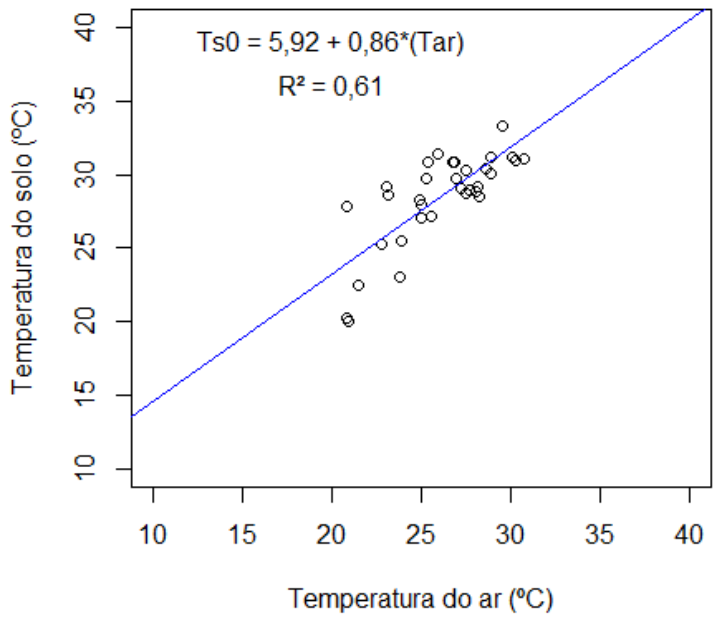

(a)

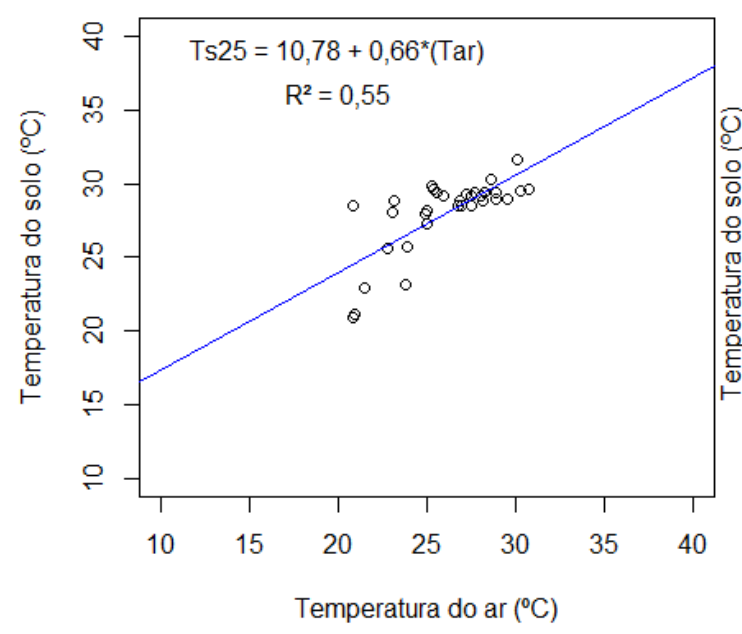

(c)

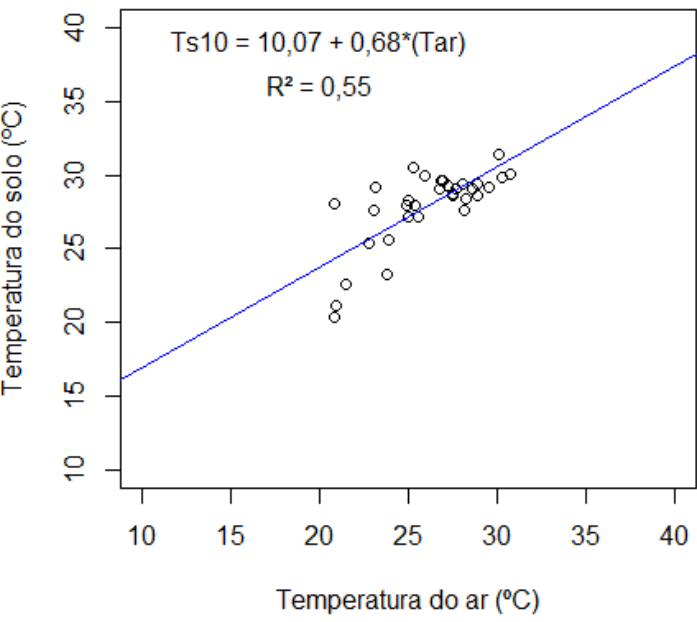

(b)

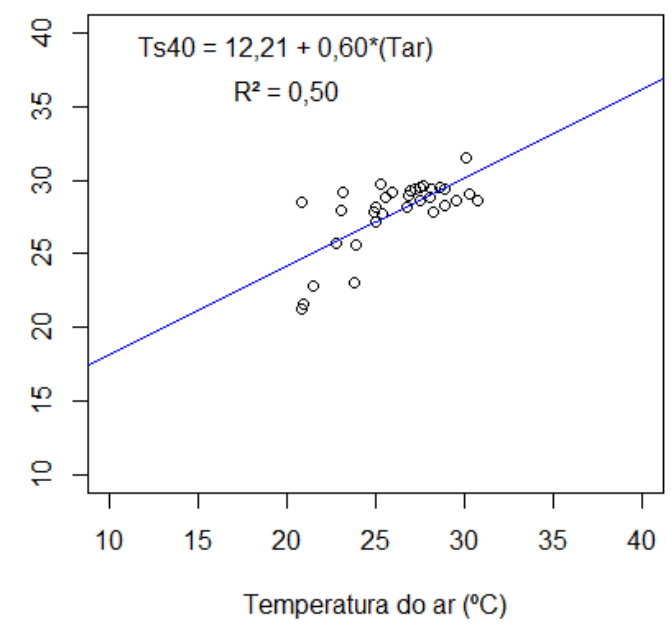

(d)

Fonte: Autores, 2019.

Para estudos de transferência de calor, o solo é considerado uma superfície sólida semiinfinita. Segundo Incropera et al. (2008), este sólido estende-se ao infinito em todas as direções, com exceção de uma, caracterizando-se por uma única superfície identificável. Quando este é submetido a uma mudança de temperatura, ocorre uma condução de calor unidimensional transiente no interior do sólido. Considerando o estudo da condução de calor no solo, o sólido semi-infinito fornece uma aproximação razoável para a porção inicial do transiente, na qual as temperaturas nas camadas mais profundas do solo, ou seja, em pontos distantes da superfície, não estão significativamente influenciadas pela mudança nas condições superficiais.

Observa-se na Figura 6, três casos de distribuição transiente de temperaturas ao longo de um sólido semi-infinito. No caso em estudo, o solo apresenta as condições ilustradas nos casos 2 e 3 , tendo em vista que a irradiação solar atua como um fluxo térmico constante sobre a superfície do 
mesmo (Caso 2), além da influência da temperatura do ar realizando trocas térmicas com o solo por meio de convecção (Caso 3).

Figura 5 - Regressão linear para o solo solarizado; (a) 0 m; (b) 0,1 m; (c) 0,25 m; (d) 0,4 m.

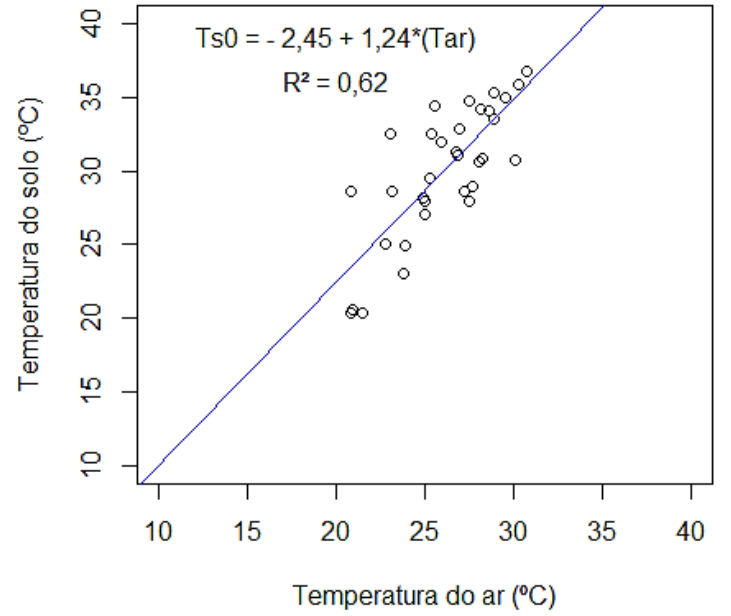

(a)

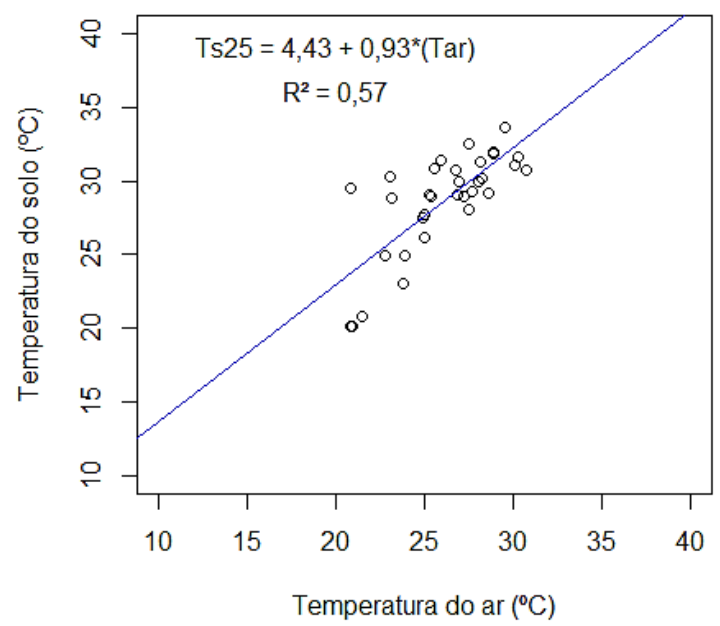

(c)

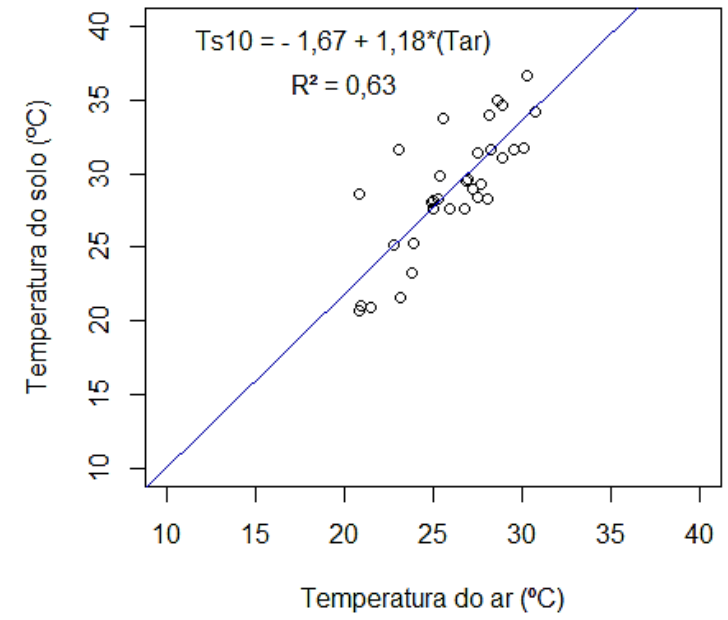

(b)

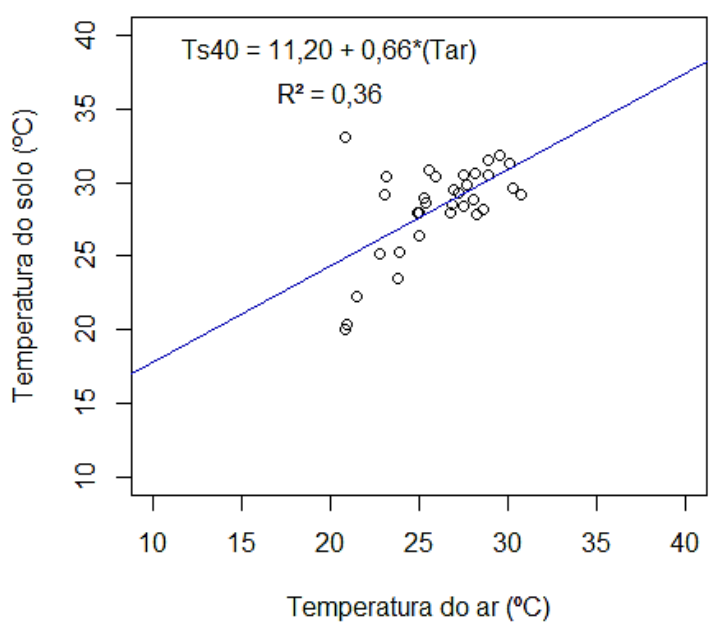

(d)

Fonte: Autores, 2019.

Figura 6 - Distribuições de temperaturas em um sólido semi-infinito para três condições na superfície: (a) temperatura na superfície constante, (b) fluxo térmico na superfície constante e (c) convecção na superfície. 


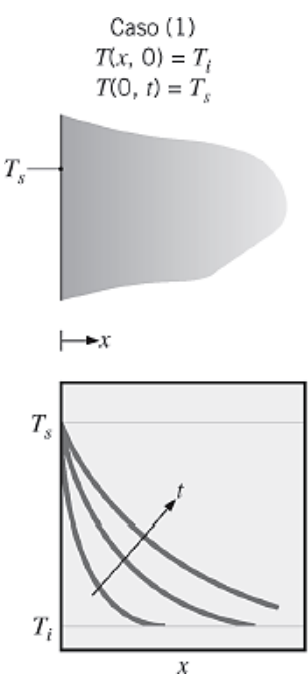

(a)

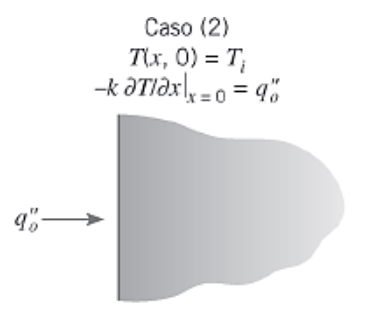

$\mapsto x$

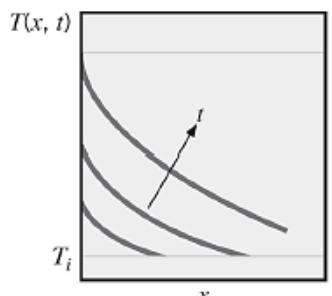

(b)

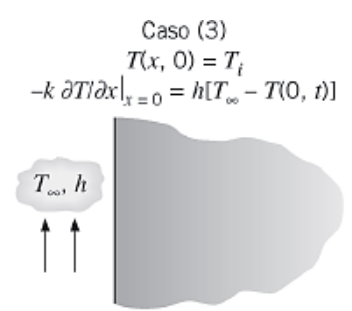

$\mapsto x$

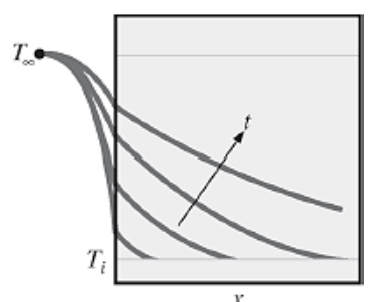

(c)

Fonte: INCROPERA et al., 2008.

Assim, as temperaturas resultantes em cada profundidade do solo dependem tanto da temperatura do ar e do seu coeficiente convectivo quanto da irradiação total que atinge a superfície. Porém, a determinação da temperatura do solo em função apenas da temperatura do ar facilita a utilização cotidiana das equações, tendo em vista a dificuldade de conhecer o coeficiente convectivo e irradiação solar sem auxílio de cálculos mais avançados, equipamentos de medição ou Estação Meteorológica. Todavia, essa simplificação pode comprometer o modelo ajustado, reduzindo o coeficiente de determinação e, consequentemente, a qualidade da estimativa pretendida.

\section{CONCLUSÃO}

Técnicas sustentáveis para produção agrícola, assim como a diminuição do uso de defensivos agrícolas ou produtos químicos que possam interferir nos diversos ecossistemas e na saúde dos seres humanos, têm sido um assunto constante na atualidade. A técnica de solarização do solo apareceu como uma alternativa para o tratamento do solo, pois é de fácil manuseio e gera bons resultados, dependendo das condições climáticas do local onde será aplicada.

A partir dos resultados, conclui-se que a solarização pode ser considerada uma técnica viável para tratamento de áreas agrícolas na região de estudo, uma vez que houve um aumento na temperatura do solo em todas as profundidades monitoradas. Porém, acredita-se que resultados mais satisfatórios seriam obtidos com um período mais longo de aplicação, além de uma área experimental mais extensa, que pode colaborar com um maior acúmulo de calor entre a superfície do terreno e o filme de polietileno.

As estimativas de temperatura do solo a partir de regressão linear podem ser consideradas aceitáveis, pois é possível observar graficamente um comportamento linear nos dados. Para elevar os coeficientes de determinação é necessário um tratamento dos dados, realizando uma análise detalhada 
dos valores outliers e remoção dos mesmos, com consequente melhora no cálculo das medidas estatísticas. Ainda, recomenda-se considerar a irradiação solar como um parâmetro adicional nas equações, visto que exerce grande influência sobre a camada superficial do solo, atuando como um fluxo contínuo de calor.

\section{REFERÊNCIAS}

AHMAD, M. F.; RASUL, G. Prediction of soil temperature by air temperature: a case study for Faisalabad. Pakistan Journal of Meteorology, v. 5, n. 9, 2008.

ASSOCIAÇÃO BRASILEIRA DE NORMAS TÉCNICAS (ABNT). NBR 14610: Indicador de temperatura com sensor - Calibração por comparação com instrumento-padrão. Rio de Janeiro, 5 p., 2000.

GAMLIEL, A.; AUSTERWEIL, M.; KRITZMAN, G. Non-chemical approach to soilborne pest management organic amendments. Crop Protection, v. 19, p. 847-853, 2000.

GHINI, R.; PATRICIO, F. R. A.; SOUZA, M. D.; SINIGAGLIA, C.; BARROS, B. C.; LOPES, M. E. B. M.; TESSARIOLI NETO, J.; CANTARELLA, H. Efeito da solarização sobre propriedades físicas, químicas e biológicas de solos. Revista Brasileira de Ciência do Solo, v. 27, n. 1, p. 71-79, 2003.

HOROWITZ, M.; REGEV, Y; HERZLINGER, G. Solarization for Weed Control. Weed Science, v. 31, p. 170-179, 1983.

INCROPERA, F. P.; DEWITT, D. P; BERGMAN, T. L.; LAVINE, A. S. Fundamentos de transferência de calor e de massa. 6 Ed. Rio de Janeiro: Editora LTC, tradução e revisão técnica de Eduardo Mach Queiroz, Fernando Luiz Pellegrini Pessoa, 663 p., 2008.

KANAAN, H.; FRENK, S.; RAVIV, M.; MEDINA, S.; MINZ, D. Long and short term effects of solarization on soil microbiome and agricultural production. Applied Soil Ecology, v. 124, p. 54-61, 2018.

KATAN, J. Solar heating (solarization) of soil for control of soilborne pests. Annual Review of Phytopathology, Palo Alto, v. 19, p. 211-236, 1981.

KUVA, M. A.; ALVES, P. L. C. A.; ERASMO, E. L. A. Efeitos da solarização do solo através de plástico transparente sobre o desenvolvimento da tiririca (Cyperus rotundus). Planta Daninha, v. 13, n. $1,1995$.

MELO, G.; MISAEL, G. Y. M.; SIQUEIRA, N. Indicadores de sustentabilidade urbana na Bacia do Rio Belém, Vila Hauer, Curitiba-PR. Revista Tecnologia e Ambiente, v. 24, p. 197-214, 2018.

MOREIRA, F. M. S.; SIQUEIRA, J. O. Microbiologia e bioquímica do solo. 2. Ed. Lavras: Editora UFLA, 729 p., 2006.

SANTOS, H. G. dos; JACOMINE, P. K. T.; ANJOS, L. H. C. dos; OlIVEIRA, V. A. de; LUMBRERAS, J. F.; COELHO, M. R.; ALMEIDA, J. A. de; ARAÚJO FILHO, J. C. de; OLIVEIRA, J. B. de; CUNHA, T. J. F. Sistema Brasileiro de Classificação de Solos (SiBCS). 5. Ed. Brasília, DF: Embrapa, 355 p., 2018.

SIMMONS, C. W.; CLAYPOOL, J. T.; MARSHALL, M. N.; JABUSCH, L. K.; REDDY, A. P.; SIMMONS, B. A.; SINGER, S. W.; STAPLETON, J. J.; VANDERGHEYNST, J. S.; 2014. Characterization of bacterial communities in solarized soil amended with lignocellulosic organic matter. Applied Soil Ecology, v. 73, p. 97-104. 